\title{
Lack of dissemination of acquired resistance to $\beta$-lactam in small wild mammals around an isolated village in the Amazonian forest
}

Nathalie Grall ${ }^{1,2,3}$, Olivier Barraud ${ }^{4,5,6}$, Ingrid Wieder ${ }^{3}$, Anna Hua ${ }^{3}$, Marion Perrier ${ }^{3}$, Ana Babosan $^{7}$, Margaux Gaschet ${ }^{4}$, Olivier Clermont ${ }^{1,2}$, Erick Denamur ${ }^{1,2}$, François Catzeflis ${ }^{8}$, Dominique Decré ${ }^{7,9,10}$, Marie-Cécile Ploy ${ }^{4,5,6}$, Antoine Andremont ${ }^{1,2,3}$

${ }^{1}$ INSERM, IAME, UMR 1137, F-75018 Paris, France

${ }^{2}$ Univ Paris Diderot, IAME, UMR 1137, Sorbonne Paris Cité, F-75018 Paris, France

${ }^{3}$ AP-HP, Hôpital Bichat, Laboratoire de Microbiologie, F-75018 Paris, France

${ }^{4}$ CHU Limoges, Laboratoire de Bactériologie-Virologie-Hygiène, Limoges, France

${ }^{5}$ INSERM U1092, Limoges, France

${ }^{6}$ Univ Limoges, UMR-S1092, Limoges, France

${ }^{7}$ AP-HP, Hôpital Saint-Antoine, Laboratoire de Bactériologie-Hygiène, F-75012 Paris, France

${ }^{8}$ CNRS UMR-5554, Institut des Sciences de l'Evolution, Univ Montpellier-2, Montpellier, France

${ }^{9}$ Sorbonne Universités, UPMC Univ Paris 06, CR7, Centre d'Immunologie et des Maladies Infectieuses, CIMI, team E13 (Bacteriology), Paris, France

${ }^{10}$ INSERM, U1135, Centre d'Immunologie et des Maladies Infectieuses, CIMI, Team E13, Paris, France

Keywords: antibiotic resistance, wild animals, selective pressure, integron

Running title: Lack of dissemination of antibiotic resistance in the wild

Corresponding author: N. Grall

Hôpital Bichat - Claude Bernard

Laboratoire de Bactériologie

46, rue Henri Huchard

75018 Paris, France

nathalie.grall@bch.aphp.fr

Tel: + 33 (0)1 40258507

Fax: + $33(0) 140258581$ 


\section{Summary}

In this study we quantitatively evaluated the spread of resistance to $\beta$-lactams and of integrons in small rodents and marsupials living at various distances from a point of antibiotic's use. Rectal swabs from 114 animals were collected in Trois-Sauts, an isolated village in French Guiana, and along a $3 \mathrm{~km}$ transect heading through the nonanthropized primary forest. Prevalence of ticarcillin resistant enterobacteria was 36\% (41/114). Klebsiella spp., naturally resistant to ticarcillin, were found in $31.1 \%(23 / 73)$ of animals from the village and in an equal ratio of $31.7 \%$ (13/41) of animals trapped along the transect. By contrast $E$. coli with acquired resistance to ticarcillin were found in $13.7 \%$ (10/73) of animals from the village and in only $2.4 \%(1 / 41)$ of those from the transect (600 $\mathrm{m}$ from the village). There was a huge diversity of $E$. coli and $K$. pneumoniae strains with very unique and infrequent sequence types. The overall prevalence of class 1 integrons carriage was $19.3 \%(22 / 114)$ homogenously distributed between animals from the village and the transect, which suggests a co-selection by a non-antibiotic environmental factor. Our results indicate that the anthropogenic acquired antibiotic resistance did not disseminate in the wild far from the point of selective pressure. 


\section{Introduction}

Antibiotic resistance is a threat to public health worldwide. Its rapid growth combined with the lack of antibiotic innovation leads to increase of infections due to totally resistant bacteria (Boucher et al., 2009). We know a great deal about the genetics and biochemistry of bacterial resistance to antibiotics but much less on the paths of dissemination of resistance genes in nature. Ancestral resistance genes have been present in environmental bacteria for very long period of time where their actual role is not fully understood (Bhullar et al., 2012). They disseminated to human bacteria only very recently. This is believe to be because resistance confers bacteria a decisive advantage to confront the antibiotic residues that are often present in the environmental and commensal ecosystems as a consequence of the human use of antibiotic, not only in medicine but also in the food-chain industry (Marshall and Levy, 2011; Lupo et al., 2012). In these ecosystems bacteria of various origins can mix and exchange resistance genes. Concerning enterobacteria which are intestinal commensal but also major potential pathogens, resistance levels are extremely alarming worldwide (Woerther et al., 2013b) and the intestinal microbiota is considered to be the "epicenter" where bacteria of various origins can exchange resistance genes and disseminate (Carlet, 2012). For instance, the transfer of bacterial resistance from animals, particularly food-chain ones, to humans through the intestinal microbiota is extensively studied to assess the risk associated with animal use of antibiotics for human health (Levy et al., 1976; Van den Bogaard et al., 1997). The reverse transfer of resistance from humans to wild animals is considered a marker of the impact of human usage of antibiotics on the environment (Skurnik et al., 2006).

Wild animals are not normally exposed to antimicrobials, but they might come in contact with resistant bacteria through direct and indirect interactions with humans and domestic animals (Marshall et al., 1990). Several studies showed higher bacterial resistance rates in wild 
animals living in close proximity to humans or agriculture compared to those living in more isolated areas (Rolland et al., 1985; Cole et al., 2005; Skurnik et al., 2006; Kozak et al., 2009; Allen et al., 2011). The presence of integrons has also been used as a marker of the level of selection pressure (Kang et al., 2005; Skurnik et al., 2006; Stalder et al., 2012). The level of bacterial resistance in the intestinal microbiota of wild animals seems to depend on the intensity of their direct contacts with human populations and secondary transmission seems rare (Sjolund et al., 2008). However, controlled studies are lacking and it is unknown how far resistance can spread in the wild through animal transmission due to the selective pressure that follows human use of antibiotics. Here we took advantage that we were studying bacterial resistance in a population of Wayampi Amerindians living isolated in the village of TroisSauts in the midst of the Amazonian forest. Resulting from the care they receive in the village health post, they are exposed to well characterized quantities of antibiotics (Woerther et al., 2010; Woerther et al., 2013a). In order to gather data on the consecutive dissemination of resistance genes we trapped small wild rodents and marsupials at various distances from the village and analyzed their feces. We explored as a model the dissemination of $\beta$-lactam resistance because it was the most commonly used class of antibiotics in the village of TroisSauts (58\% of all treatments) followed by metronidazole (21\%) and macrolides (11\%). Others antibiotics (ofloxacin, doxycycline, cotrimoxazole and nitroxoline) were anecdotal (Woerther et al., 2010). $\beta$-lactam resistance was analyzed in E. coli on one hand and in Klebsiella spp. on the other, taking advantage that it is an acquired trait in E. coli whereas it is a natural trait in Klebsiella spp. 


\section{Results and discussion}

The sampling was performed during three campaigns (October 2006, June 2008, and October 2010) that we carried out in the village of Trois-Sauts (in the municipality of Camopi, French Guiana: $02^{\circ} 15^{\prime} \mathrm{N}, 52^{\circ} 52^{\prime} \mathrm{W}$ ) where we were studying bacterial resistance in the microbiota of the villagers (Skurnik et al., 2008; Ruimy et al., 2010; Woerther et al., 2010; Catzeflis, 2012; Lebeaux et al., 2012; Angebault et al., 2013; Lescat et al., 2013; Woerther et al., 2013a). The setting is rather unique because it combines the presence of an isolated and stable human population still living in a traditional manner in a completely wild forestall environment. However, this population is exposed to antibiotics due to the presence in the village of a health post where a resident paramedic treats villagers with antibiotics when necessary. In all, we collected 114 small wild mammals (rodents and marsupials) known to have a limited perimeter of life of few hectares (Catzeflis F., personal communication) by setting traps in the village (73 animals) and every $300 \mathrm{~m}$ from the village in a standardized manner (Mauffrey et al., 2007; Catzeflis, 2012) along a 3000m transect that we draw in the forest in non anthropized zones (41 animals) (Fig. 1 and Table S1). There were 100 rodents and 14 marsupials, speciated as described (Voss et al., 2001; Wilson and Reeder, 2005; Weksler et al., 2006; Voss and Jansa, 2009), including 38 Nectomys rattus, 22 Proechimys cuvieri, 13 Oecomys bicolor, 13 Hylaeamys megacephalus, 4 Oecomys rutilus, 4 Proechimys guyanensis, 2 Euryoryzomys macconnelli, 2 Makalata didelphoides, 1 Neacomys paracou, 1 Neusticomys oyapocki, 8 Marmosa murina, 2 Philander opossum, 1 Marmosops pinheiroi, 1 Didelphis imperfecta, 1 Didelphis marsupialis and 1 Marmosa demerarae. A rectal swab was performed on each captured animal before it was released after being marked to avoid sampling twice the same animal. 
122

123

124

All samples analyzed contained viable enterobacteria. Ticarcillin resistant enterobacteria were detected in 41/114 (36\%) samples. The resistant species were Klebsiella spp. only in 30/114 (26.3\%) samples, E. coli only in 5/114 (4.4\%) samples and both in 6/114 (5.3\%) samples. However, there were notable differences in the spatial distribution of the two species. Naturally resistant Klebsiella spp. strains were found in 23/73 (31.5\%) samples from animals trapped in the village and in a very close ratio of $13 / 41(31.7 \%)$ from those from animals trapped elsewhere along the transect (Tables 1, and S1). Moreover, the percentages did not vary significantly with increasing distance from the village, being 2/14 (14.3\%), 4/12 (33.3\%) and $7 / 15(46.7 \%)$ on the $1^{\text {st }}$, the $2^{\text {nd }}$ and the $3^{\text {rd }}$ kilometers of the transect respectively (Fig. 2 ). By contrast, E. coli isolates with acquired resistance to ticarcillin were found in 10/73 (13.7\%) samples from animals trapped in the village, but in only $1 / 41(2.4 \%)$ of those from elsewhere along the transect, at $600 \mathrm{~m}$ from the village. As a reminder, the rate of this type of resistance in the dominant E. coli from the villagers was $20.4 \%$ (Lescat et al., 2013).

Our current results indicate that acquired resistance to $\beta$-lactams did not spread far from the point of selective pressure in the wild. This probably results from cost fitness of acquired antibiotic resistance in the absence of selective pressure. Several studies have already shown in a qualitative way that the level of antibiotic resistance in the microbiota of wild animals is higher in those living in close proximity to human's activity than in those without contact with humans (Rolland et al., 1985; Cole et al., 2005; Skurnik et al., 2006; Kozak et al., 2009; Allen et al., 2011). However, to our knowledge, our study is the first to assess quantitatively that acquired resistance to $\beta$-lactam does not disseminate far in the wild in absence of selective pressure.

Resistance to third generation cephalosporins was not detected in any sample. 
A total of 16 ticarcillin resistant $E$. coli strains were isolated from the 11 ticarcillin resistant $E$. coli positive samples. A TEM-1 penicillinase conferring resistance to amoxicillin and ticarcillin was present in all strains. Five (31.2\%) were susceptible to all the others antibiotics tested (Table 2) while 7 (43.7\%), including the one from the $600 \mathrm{~m}$ point (Ec-600-1), were coresistant to trimethoprim and sulfonamides. The 4 remaining strains had each a unique pattern of co-resistance, combining sulfonamides and/or trimethoprim and/or tetracycline and/or kanamycin. Nine strains belonged to the two phylogroups most often shared by commensal $E$. coli, i.e. groups A (4 strains) and B1 (5 strains) while 3 strains were from group C, 2 from group D and 2 from group E (Table 2). Of note, no B2 strain was found. A high genetic diversity was observed. Indeed, except for 2 sequence type (ST) 2690 strains that were indistinguishable by rep-PCR (Ec-0-5 and Ec-0-12 from the village), each strain had a distinct rep-pattern (Fig. 3 (a)). Strains Ec-0-1 and Ec-0-15, both isolated from animals trapped in the village, were from ST155 but had different rep-patterns and antibiotic susceptibilities. The 12 other strains had each a unique ST and half of them had never been described. Furthermore, the $\operatorname{gyr} B$ allele of Ec-0-4 had not been reported before. In all, $42.8 \%(6 / 14)$ of the ST found in these animal strains had never been described, in accordance with a previous work in the same region (Lescat et al., 2013). The mean virulence score in these 16 strains was low at 1.3 (range 0 to 4 ), with mainly virulence determinants involved in iron capture. The most frequent virulence genes were $f y u A$ and irp2, which belong to the high pathogenicity island (HPI) found in enterobacteria. A great diversity was also observed among plasmid carrying bla TEM-1. The most commonly occurring TEM-1 plasmid replicon was IncHI1 (5 strains), followed by IncX (4 strains), IncFII (3 strains), IncFIA (1 strain) and IncB/O (1 strain). The replicons could not be determined for 5/16 (31.2\%) strains. All incompatibility groups detected had been previously described in human and animal enterobacteria strains. However, the 
distribution was unusual: no IncFIB and few IncFII were found in favor of IncHI1 (Johnson et al., 2007; Marcade et al., 2009). The diversity of plasmid replicons could also be explained by the diversity and connectivity of gamma-proteobacteria in the wild forest environment, resulting in highly promiscuous exchange of mobile genetic elements. The huge genetic diversity among the 16 ticarcillin resistant $E$. coli strains and their plasmids suggests that the dissemination of ticarcillin resistance was more likely due to bla $a_{\mathrm{TEM}-1}$, maybe trough Tn3-type transpon (Marcade et al., 2009), than bacterial strains or plasmids spread.

A total of 36 Klebsiella spp. strains were isolated, including $34 \mathrm{~K}$. pneumoniae and $2 \mathrm{~K}$. oxytoca. A high genetic diversity without clonal spread was also observed among the $34 \mathrm{~K}$. pneumoniae strains (Fig. 3(b) and Table 3) with only one pair sharing the same rep-patterns and the same ST (Kp-2400-2 and Kp-2400-3 from 2 samples from the $2400 \mathrm{~m}$ point). Two others pairs shared the same ST but a different rep-pattern (Kp-0-22 and Kp-600-1; Kp-0-9 and Kp-2400-5). Each of the 28 remaining strains had a distinct ST. Among the 31 unique STs found, 24 (77.4\%) were described for the first time, with new alleles for 7 of them. All strains had the usual natural resistance phenotype of Klebsiella spp., i.e. resistance to amoxicillin and ticarcillin, with no co-resistance. All carried the entB siderophore gene and the $y c f M$ adhesin gene, $27 / 34(79.4 \%)$ the $k p n$ adhesin gene, $24 / 34(70.6 \%)$ the fimbriae fimH1 gene and $26 / 34(76.5 \%)$ the $k f u A B C$ gene (Table 3$)$. There was no phenotypically hypermucoviscious strain and $\operatorname{mag} A$ (specific for $\mathrm{K} 1$ serotype) or $\operatorname{rmp} A$ genes which are associated with this phenotype were not detected in any strain. Interestingly, 3 of these commensal strains from wild rodents (3 Proechimys cuvieri, 2 from the $2400 \mathrm{~m}$ point and one from the village) had the allS gene which had been strongly associated with strains isolated from liver abscess (Chou et al., 2004). Furthermore, one strain had the $y b t$ S gene (Proechimys cuvieri from the $2100 \mathrm{~m}$ point), which comes from the Ybt operons of the HPI cited above (Geoffroy et al., 2000). Capsular serotype was determined for two strains, Kp-0-8 (K20) and 
Kp-0-17 (K5) from two animals trapped in the village. No strain from capsular serotype K1, K2, K54 or K57 was found. Altogether this showed that the E. coli and K. pneumoniae strains from these wild animals were particular and unfrequently described. It also suggested that the known ST-types are those prevalent in developed countries and that the number of different niches allowing enterobacteria proliferation is much larger in this complex forest environment, explaining enterobacteria local specialization and diversification. However, all the $K$. pneumoniae strains had the entB siderophore gene, and frequently the $k p n$ and $y c f M$ adhesin genes, fimbriae $f i m H 1$ and $k f u A B C$ genes, just as strains of human origin.

\section{Detection of intestinal carriage of bla $_{\mathrm{TEM}}$}

We further investigated carriage by the animals of bla TEM gene by PCR screening of the global Drigalski culture from each sample. We found only 5 positive samples, all from animals trapped in the village and none from animals living in any other place on the transect (data not shown). Ticarcillin resistant E. coli strains had indeed been isolated in these 5 samples. By contrast the bla TEM PCR was negative in the 6 other samples from animals in whom ticarcillin resistant $E$. coli strains had also been isolated, including the one trapped at $600 \mathrm{~m}$ from the village. This suggests that PCR on global Drigalski cultures was less sensitive than further screening of these cultures on selective media and performing PCR on the resulting strains for detection of $b l a_{\mathrm{TEM}}$ genes.

\section{Prevalence of class 1, 2 and 3 integrons and gene cassettes characterization}

We also investigated the carriage by the animals of class 1, 2 and 3 integrons by multiplex qPCR screening of the global Drigalski culture from each sample. Class 1 integrons were detected in 22/114 (19.3\%) of the samples, with no significant difference between those from animals trapped in the village or along the transect (11/73 (15.1\%) vs $11 / 41(26.8 \%))$ (Tables 
1 and S1). There was no detectable spatial distribution along it either, the prevalence being of $4 / 14(28.6 \%), 2 / 12(16.7 \%) 5 / 15(33.3 \%)$ for the $1^{\text {st }}, 2^{\text {nd }}$ and $3^{\text {rd }}$ kilometers of the transect respectively (Fig. 4). Class 2 integrons, which were not further studied, were detected in 3 samples only, coming from one animal trapped in the village, one at the $300 \mathrm{~m}$ point and one at the $2400 \mathrm{~m}$ point. No class 3 integron was detected. The homogenous distribution of class 1 integrons between the village and the transect, independently of antibiotic selective pressure, is in appearance strikingly different from the heterogeneous distribution of acquired resistance described in previous studies (Cole et al., 2005; Skurnik et al., 2006), which found that integrons were only present when antibiotic selective pressure exceeds a certain threshold. The analysis of the gene cassettes in class 1 integrons showed little diversity with seven different gene cassette arrays (Table 4). The gene cassettes encoded resistance to trimethoprim (drfA7, dfrA15, dfrA21), spectinomycin and streptomycin (aadA1, aadA2, aadA6) or chloramphenicol ( $\mathrm{cmlA4})$. aadA6 was the most frequently found gene cassette $(6 / 22(27.3 \%))$. One sample (Oecomys rutilus) from the $2400 \mathrm{~m}$ trapping point had 2 different integrons, one with the $d f_{r} A 21$ gene cassette and one with the addAl gene cassette. However, we were not able to characterize the gene cassette arrays for 8/22 (36\%) class 1 integronpositive samples because we failed to obtain amplification products with the endpoint PCR with 5'CS and 3'CS primers. We can hypothesize that these integrons do not contain the 3'conserved segment in which the 3' CS primer hybridizes, as described especially for class 1 integrons detected in non-clinical strains (Gillings et al., 2008). The genes cassette found in these integrons were coding for resistance towards antibiotics which were not used in the village. The presence of integrons carrying resistance gene cassettes in the intestinal microbiota of wild animals not exposed to antibiotic selective pressure has been observed before (Sunde, 2005; Goncalves et al., 2013) but its significance has yet to be elucidated. All genes cassette detected had been previously described in human or animal commensal strains 
(Kang et al., 2005; Peirano et al., 2006; Kadlec and Schwarz, 2008; Michael et al., 2008). It is

of note that the method used didn't allowed to characterize the gene cassette arrays for $8 / 22$

$(36 \%)$ class 1 integron positive samples, thus we cannot rule out that other gene cassettes could have been present there.

\section{Detection of $\operatorname{mer} A$}

We hypothesized that the stable prevalence of class 1 integrons in the village and along the transect could be due to a co-selection by mercury. Indeed, the mer operon encoding for mercury resistance has often been described as associated to class 1 integron within the $\operatorname{Tn} 21$ like transposon (Skurnik et al., 2006; Skurnik et al., 2010) and this region of French Guiana has been heavily exposed to mercury in the past, because of gold mining prospection (Laperche et al., 2014).

This was tested by screening the global Drigalski culture from each sample and the 16 ticarcillin resistant E. coli strains for merA gene by PCR amplification as described (Deredjian et al., 2011). However, we found only 1 sample positive, (from a Makalata didelphoides, which is an arboreal echimyid Caviomorpha, trapped in the village) and none of the strains were positive (data not shown). Thus, class 1 integrons might have been selected by a nonantibiotic environmental factor which remains to be determined. It could also reflect other opportunities in such a complex environment for spontaneous horizontal genetic transfer and random drift-based enrichment of transconjugants.

Certainly our study was limited by the relatively small number of samples available from the transect. This was in spite of considerable efforts of trapping (Table S2) whose yield was low. 
271 rodents and marsupials in the forest was probably due to reduced food resources (Catzeflis F.,

272 personal communication). Another limitation of our work was that we studied the resistance

273 to only one class of antibiotic, the $\beta$-lactam. But resistance to $\beta$-lactam was chosen as a model

274 because it was by far the most frequent antibiotics used in the village. Despite these

275 limitations, our results suggest that acquired resistance genes do not diffuse when antibiotic

276 selective pressure stops which is a strong incentive to control the use of antibiotics and all

277 kind of release of these molecules in the environment. 


\section{Acknowledgments/Funding}

279 We thank the villagers for their help and their warm welcome and Gilles Peroz for excellent 280 technical assistance. We are very grateful to Sylvie Nazaret and Catherine Branger for their 281 help and technical support on mercury resistance and plasmid characterization respectively. 282 The ERAES project was supported in part by the Agence Française de Sécurité Sanitaire de 283 l'Environnement et du Travail (contracts ES-05-01 and EST-09-21), the Agence Nationale 284 pour la Recherche (contract 05-9-114), the Institut National de la Santé et de la Recherche 285 Médicale (INSERM; contracts C06-18 and C10-19), the Centre National de Référence 286 "Résistance bactérienne dans les flores commensales", and the French government's 287 investissement d'Avenir program, Laboratoire d'Excellence "Integrative Biology of Emerging 288 Infectious Diseases" (grant ANR-10-LABX-62-IBEID). This work was also supported in part 289 by EU-FP7 projects EVOTAR and R-Gnosis

\section{Potential conflict of interest}

All authors: No reported conflicts.

294 This work has been presented at the $34^{\text {th }}$ RICAI, 2014 Nov. 27-28, Paris. 
Allen, S.E., Boerlin, P., Janecko, N., Lumsden, J.S., Barker, I.K., Pearl, D.L., et al. (2011). Antimicrobial Resistance in Generic Escherichia coli Isolates from Wild Small Mammals Living in Swine Farm, Residential, Landfill, and Natural Environments in Southern Ontario, Canada. Appl Environ Microbiol 77: 882-888.

Angebault, C., Djossou, F., Abelanet, S., Permal, E., Ben Soltana, M., Diancourt, L., et al. (2013). Candida albicans Is Not Always the Preferential Yeast Colonizing Humans: A Study in Wayampi Amerindians. J Infect Dis 208: 1705-1716.

Bachman, M.A., Oyler, J.E., Burns, S.H., Caza, M., Lepine, F., Dozois, C.M., and Weiser, J.N. (2011). Klebsiella pneumoniae Yersiniabactin Promotes Respiratory Tract Infection through Evasion of Lipocalin 2. Infect Immun 79: 3309-3316.

Bakour, R., Laroche, Y., and Cornelis, G. (1983). Study of the Incompatibility and Replication of the 70-Kb Virulence Plasmid of Yersinia. Plasmid 10: 279-289.

Barraud, O., Baclet, M.C., Denis, F., and Ploy, M.C. (2010). Quantitative Multiplex RealTime PCR for Detecting Class 1, 2 and 3 Integrons. J Antimicrob Chemother 65: 1642-1645. Bhullar, K., Waglechner, N., Pawlowski, A., Koteva, K., Banks, E.D., Johnston, M.D., et al. (2012). Antibiotic Resistance Is Prevalent in an Isolated Cave Microbiome. PLoS One 7: e34953.

Boucher, H.W., Talbot, G.H., Bradley, J.S., Edwards, J.E., Gilbert, D., Rice, L.B., et al. (2009). Bad Bugs, No Drugs: No Eskape! An Update from the Infectious Diseases Society of America. Clin Infect Dis 48: 1-12.

Brisse, S., Fevre, C., Passet, V., Issenhuth-Jeanjean, S., Tournebize, R., Diancourt, L., and Grimont, P. (2009). Virulent Clones of Klebsiella pneumoniae: Identification and Evolutionary Scenario Based on Genomic and Phenotypic Characterization. PLoS One 4: e4982.

Carattoli, A., Bertini, A., Villa, L., Falbo, V., Hopkins, K.L., and Threlfall, E.J. (2005). Identification of Plasmids by PCR-Based Replicon Typing. J Microbiol Methods 63: 219-228. Carlet, J. (2012). The Gut Is the Epicentre of Antibiotic Resistance. Antimicrob Resist Infect Control 1: 39 .

Catzeflis, F. (2012). A Survey of Small Non-Volant Mammals Inhabiting Wayampi Amerindian Houses in French Guiana. Mammalia 76: 327-330.

Chen, Y.T., Chang, H.Y., Lai, Y.C., Pan, C.C., Tsai, S.F., and Peng, H.L. (2004). Sequencing and Analysis of the Large Virulence Plasmid pLVPK of Klebsiella pneumoniae CG43. Gene 337: 189-198.

Chou, H.C., Lee, C.Z., Ma, L.C., Fang, C.T., Chang, S.C., and Wang, J.T. (2004). Isolation of a Chromosomal Region of Klebsiella pneumoniae Associated with Allantoin Metabolism and Liver Infection. Infect Immun 72: 3783-3792.

Clermont, O., Christenson, J.K., Denamur, E., and Gordon, D.M. (2013). The Clermont Escherichia coli Phylo-Typing Method Revisited: Improvement of Specificity and Detection of New Phylo-Groups. Environ Microbiol Rep 5: 58-65.

Cole, D., Drum, D.J., Stalknecht, D.E., White, D.G., Lee, M.D., Ayers, S., et al. (2005). Free-Living Canada Geese and Antimicrobial Resistance. Emerg Infect Dis 11: 935-938. Deredjian, A., Colinon, C., Brothier, E., Favre-Bonte, S., Cournoyer, B., and Nazaret, S. (2011). Antibiotic and Metal Resistance among Hospital and Outdoor Strains of Pseudomonas aeruginosa. Res Microbiol 162: 689-700.

Fang, C.T., Chuang, Y.P., Shun, C.T., Chang, S.C., and Wang, J.T. (2004). A Novel Virulence Gene in Klebsiella pneumoniae Strains Causing Primary Liver Abscess and Septic Metastatic Complications. J Exp Med 199: 697-705. 
Geoffroy, V.A., Fetherston, J.D., and Perry, R.D. (2000). Yersinia pestis Ybtu and Ybtt Are Involved in Synthesis of the Siderophore Yersiniabactin but Have Different Effects on Regulation. Infect Immun 68: 4452-4461.

Gillings, M., Boucher, Y., Labbate, M., Holmes, A., Krishnan, S., Holley, M., and Stokes, H.W. (2008). The Evolution of Class 1 Integrons and the Rise of Antibiotic Resistance. J Bacteriol 190: 5095-5100.

Goncalves, A., Igrejas, G., Radhouani, H., Santos, T., Monteiro, R., Pacheco, R., et al. (2013). Detection of Antibiotic Resistant Enterococci and Escherichia coli in Free Range Iberian Lynx (Lynx pardinus). Sci Total Environ 456-457: 115-119.

Johnson, J.R., Clermont, O., Menard, M., Kuskowski, M.A., Picard, B., and Denamur, E. (2006). Experimental Mouse Lethality of Escherichia coli Isolates, in Relation to Accessory Traits, Phylogenetic Group, and Ecological Source. J Infect Dis 194: 1141-1150. Johnson, T.J., Wannemuehler, Y.M., Johnson, S.J., Logue, C.M., White, D.G., Doetkott, C., and Nolan, L.K. (2007). Plasmid Replicon Typing of Commensal and Pathogenic Escherichia coli Isolates. Appl Environ Microbiol 73: 1976-1983.

Kadlec, K., and Schwarz, S. (2008). Analysis and Distribution of Class 1 and Class 2 Integrons and Associated Gene Cassettes among Escherichia coli Isolates from Swine, Horses, Cats and Dogs Collected in the BfT-GermVet Monitoring Study. J Antimicrob Chemother 62: 469-473.

Kang, H.Y., Jeong, Y.S., Oh, J.Y., Tae, S.H., Choi, C.H., Moon, D.C., et al. (2005). Characterization of Antimicrobial Resistance and Class 1 Integrons Found in Escherichia coli Isolates from Humans and Animals in Korea. J Antimicrob Chemother 55: 639-644.

Kozak, G.K., Boerlin, P., Janecko, N., Reid-Smith, R.J., and Jardine, C. (2009). Antimicrobial Resistance in Escherichia coli Isolates from Swine and Wild Small Mammals in the Proximity of Swine Farms and in Natural Environments in Ontario, Canada. Appl Environ Microbiol 75: 559-566.

Laperche, V., Hellal, J., Maury-Brachet, R., Joseph, B., Laporte, P., Breeze, D., and Blanchard, F. (2014). Regional Distribution of Mercury in Sediments of the Main Rivers of French Guiana (Amazonian Basin). Springerplus 3: 322.

Lebeaux, D., Barbier, F., Angebault, C., Benmahdi, L., Ruppe, E., Felix, B., et al. (2012). Evolution of Nasal Carriage of Methicillin-Resistant Coagulase-Negative Staphylococci in a Remote Population. Antimicrob Agents Chemother 56: 315-323.

Lefort, A., Panhard, X., Clermont, O., Woerther, P.L., Branger, C., Mentre, F., et al. (2011). Host Factors and Portal of Entry Outweigh Bacterial Determinants to Predict the Severity of Escherichia coli Bacteremia. J Clin Microbiol 49: 777-783.

Lescat, M., Clermont, O., Woerther, P.L., Glodt, J., Dion, S., Skurnik, D., et al. (2013). Commensal Escherichia coli Strains in Guiana Reveal a High Genetic Diversity with HostDependant Population Structure. Environ Microbiol Rep 5: 49-57.

Levesque, C., Piche, L., Larose, C., and Roy, P.H. (1995). PCR Mapping of Integrons Reveals Several Novel Combinations of Resistance Genes. Antimicrob Agents Chemother 39: 185-191.

Levy, S.B., FitzGerald, G.B., and Macone, A.B. (1976). Changes in Intestinal Flora of Farm Personnel after Introduction of a Tetracycline-Supplemented Feed on a Farm. N Engl J Med 295: 583-588.

Lupo, A., Coyne, S., and Berendonk, T.U. (2012). Origin and Evolution of Antibiotic Resistance: The Common Mechanisms of Emergence and Spread in Water Bodies. Front Microbiol 3: 18. 
Marcade, G., Deschamps, C., Boyd, A., Gautier, V., Picard, B., Branger, C., et al. (2009). Replicon Typing of Plasmids in Escherichia coli Producing Extended-Spectrum BetaLactamases. J Antimicrob Chemother 63: 67-71.

Marshall, B., Petrowski, D., and Levy, S.B. (1990). Inter- and Intraspecies Spread of Escherichia coli in a Farm Environment in the Absence of Antibiotic Usage. Proc Natl Acad Sci U S A 87: 6609-6613.

Marshall, B.M., and Levy, S.B. (2011). Food Animals and Antimicrobials: Impacts on Human Health. Clin Microbiol Rev 24: 718-733.

Mauffrey, J.F., Steiner, C., and Catzeflis, F. (2007). Small-Mammal Diversity and Abundance in a French Guianan Rain Forest: Test of Sampling Procedures Using Species Rarefaction Curves. Journal of Tropical Ecology 23: 419-425.

Michael, G.B., Cardoso, M., and Schwarz, S. (2008). Molecular Analysis of Multiresistant Porcine Salmonella enterica subsp. enterica Serovar Bredeney Isolates from Southern Brazil: Identification of Resistance Genes, Integrons and a Group II Intron. Int J Antimicrob Agents 32: $120-129$.

Peirano, G., Agerso, Y., Aarestrup, F.M., dos Reis, E.M., and dos Prazeres Rodrigues, D. (2006). Occurrence of Integrons and Antimicrobial Resistance Genes among Salmonella enterica from Brazil. J Antimicrob Chemother 58: 305-309.

Rolland, R.M., Hausfater, G., Marshall, B., and Levy, S.B. (1985). Antibiotic-Resistant Bacteria in Wild Primates: Increased Prevalence in Baboons Feeding on Human Refuse. Appl Environ Microbiol 49: 791-794.

Ruimy, R., Angebault, C., Djossou, F., Dupont, C., Epelboin, L., Jarraud, S., et al. (2010). Are Host Genetics the Predominant Determinant of Persistent Nasal Staphylococcus aureus Carriage in Humans? J Infect Dis 202: 924-934.

Saladin, M., Cao, V.T., Lambert, T., Donay, J.L., Herrmann, J.L., Ould-Hocine, Z., et al. (2002). Diversity of CTX-M Beta-Lactamases and Their Promoter Regions from Enterobacteriaceae Isolated in Three Parisian Hospitals. FEMS Microbiol Lett 209: 161-168. Sjolund, M., Bonnedahl, J., Hernandez, J., Bengtsson, S., Cederbrant, G., Pinhassi, J., et al. (2008). Dissemination of Multidrug-Resistant Bacteria into the Arctic. Emerg Infect Dis 14: 70-72.

Skurnik, D., Bonnet, D., Bernede-Bauduin, C., Michel, R., Guette, C., Becker, J.M., et al. (2008). Characteristics of Human Intestinal Escherichia coli with Changing Environments. Environ Microbiol 10: 2132-2137.

Skurnik, D., Ruimy, R., Andremont, A., Amorin, C., Rouquet, P., Picard, B., and Denamur, E. (2006). Effect of Human Vicinity on Antimicrobial Resistance and Integrons in Animal Faecal Escherichia coli. J Antimicrob Chemother 57: 1215-1219.

Skurnik, D., Ruimy, R., Ready, D., Ruppe, E., Bernede-Bauduin, C., Djossou, F., et al. (2010). Is Exposure to Mercury a Driving Force for the Carriage of Antibiotic Resistance Genes? J Med Microbiol 59: 804-807.

Stalder, T., Barraud, O., Casellas, M., Dagot, C., and Ploy, M.C. (2012). Integron Involvement in Environmental Spread of Antibiotic Resistance. Front Microbiol 3: 119. Stalder, T., Barraud, O., Jove, T., Casellas, M., Gaschet, M., Dagot, C., and Ploy, M.C. (2013). Quantitative and Qualitative Impact of Hospital Effluent on Dissemination of the Integron Pool. ISME J 8: 768-777.

Sunde, M. (2005). Class I Integron with a Group II Intron Detected in an Escherichia coli Strain from a Free-Range Reindeer. Antimicrob Agents Chemother 49: 2512-2514.

Turton, J.F., Baklan, H., Siu, L.K., Kaufmann, M.E., and Pitt, T.L. (2008). Evaluation of a Multiplex PCR for Detection of Serotypes K1, K2 and K5 in Klebsiella sp. And Comparison of Isolates within These Serotypes. FEMS Microbiol Lett 284: 247-252. 
Van den Bogaard, A.E., Jensen, L.B., and Stobberingh, E.E. (1997). VancomycinResistant Enterococci in Turkeys and Farmers. N Engl J Med 337: 1558-1559.

Voss, R.S., and Jansa, S.A. (2009). Phylogenetic Relationships and Classification of Didelphid Marsupials, an Extant Radiation of New World Metatherian Mammals, Bull. American Museum Natural History 322: 1-177.

Voss, R.S., Lunde, D.P., and Simmons, B. (2001). The Mammals of Paracou, French Guiana: A Neotropical Lowland Rainforest Fauna. Part 2: Nonvolant Species., Bull. American Museum Natural History 263: 1-236.

Weksler, M., Percequillo, A.R., and Voss, R.S. (2006). Ten New Genera of Oryzomyine Rodents (Cricetidae: Sigmodontinae). American Museum Novitates 3537: 1-29.

Wilson, D.E., and Reeder, D.M. (2005). Mammal Species of the World. A Taxonomic and Geographic Reference. The Johns Hopkins University Press, Baltimore: 1-2142.

Wirth, T., Falush, D., Lan, R., Colles, F., Mensa, P., Wieler, L.H., et al. (2006). Sex and Virulence in Escherichia coli: An Evolutionary Perspective. Mol Microbiol 60: 1136-1151. Woerther, P.L., Angebault, C., Jacquier, H., Clermont, O., El Mniai, A., Moreau, B., et al. (2013a). Characterization of Fecal ESBL-Producing Escherichia coli in a Remote Community During a Long Term Period. Antimicrob Agents Chemother 57: 5060-5066. Woerther, P.L., Angebault, C., Lescat, M., Ruppe, E., Skurnik, D., Mniai, A.E., et al. (2010). Emergence and Dissemination of Extended-Spectrum Beta-Lactamase-Producing Escherichia coli in the Community: Lessons from the Study of a Remote and Controlled Population. J Infect Dis 202: 515-523.

Woerther, P.L., Burdet, C., Chachaty, E., and Andremont, A. (2013b). Trends in Human Fecal Carriage of Extended-Spectrum Beta-Lactamases in the Community: Toward the Globalization of CTX-M. Clin Microbiol Rev 26: 744-758.

Yu, W.L., Ko, W.C., Cheng, K.C., Lee, C.C., Lai, C.C., and Chuang, Y.C. (2008). Comparison of Prevalence of Virulence Factors for Klebsiella pneumoniae Liver Abscesses between Isolates with Capsular K1/K2 and Non-K1/K2 Serotypes. Diagn Microbiol Infect Dis 62: 1-6. 


\begin{tabular}{ccccccc}
$\begin{array}{c}\text { Distance from } \\
\text { the village (m) }\end{array}$ & $\begin{array}{c}\text { Number of } \\
\text { samples }\end{array}$ & $\begin{array}{c}\text { Ticarcillin } \\
\text { resistance } \\
\text { Natural } \\
\mathrm{n}(\%)\end{array}$ & $\begin{array}{c}\text { Acquired } \\
\mathrm{n}(\%)\end{array}$ & $\begin{array}{c}\text { Class 1 } \\
\mathrm{n}(\%)\end{array}$ & $\begin{array}{c}\text { Class 2 } \\
\mathrm{n}(\%)\end{array}$ & $\begin{array}{c}\text { Class 3 } \\
\mathrm{n}(\%)\end{array}$ \\
\hline 0 & 73 & $23(31.5)$ & $10(13.7)$ & $11(15.1)$ & $1(1.4)$ & $0(0)$ \\
300 & 4 & $0(0)$ & $0(0)$ & $2(50)$ & $1(25)$ & $0(0)$ \\
600 & 9 & $2(22.2)$ & $1(11.1)$ & $2(22.2)$ & $0(0)$ & $0(0)$ \\
900 & 1 & $0(0)$ & $0(0)$ & $0(0)$ & $0(0)$ & $0(0)$ \\
1200 & 11 & $3(27.3)$ & $0(0)$ & $2(18.2)$ & $0(0)$ & $0(0)$ \\
1500 & 1 & $1(100)$ & $0(0)$ & $0(0)$ & $0(0)$ & $0(0)$ \\
2100 & 1 & $1(100)$ & $0(0)$ & $0(0)$ & $0(0)$ & $0(0)$ \\
2400 & 11 & $6(54.5)$ & $0(0)$ & $5(45.5)$ & $1(9.1)$ & $0(0)$ \\
2700 & 1 & $0(0)$ & $0(0)$ & $0(0)$ & $0(0)$ & $0(0)$ \\
3000 & 2 & $0(0)$ & $0(0)$ & $0(0)$ & $0(0)$ & $0(0)$
\end{tabular}

472
Table 1: Frequencies of natural and acquired ticarcillin resistance and of class 1, 2 and 3 integrons in microbiota of rodents and marsupials trapped in the village of Trois-Sauts and at specific distances from the village, i.e. the source of antibiotic selection pressure.

${ }^{a}$ Presence of ticarcillin resistant enterobacteria in the samples was screened by plating the global culture on Drigalski agar plates containing ticarcillin $(32 \mathrm{mg} / \mathrm{L})$.

${ }^{\mathrm{b}}$ The carriage of class 1, 2, and 3 integrons by animals was detected on total DNA extracted from the global Drigalski culture by a multiplex Taqman-based qPCR with amplification of intI1, intI2, and intI3 genes, as described (Barraud et al., 2010). 
Virulence factors ${ }^{\mathrm{b}}$

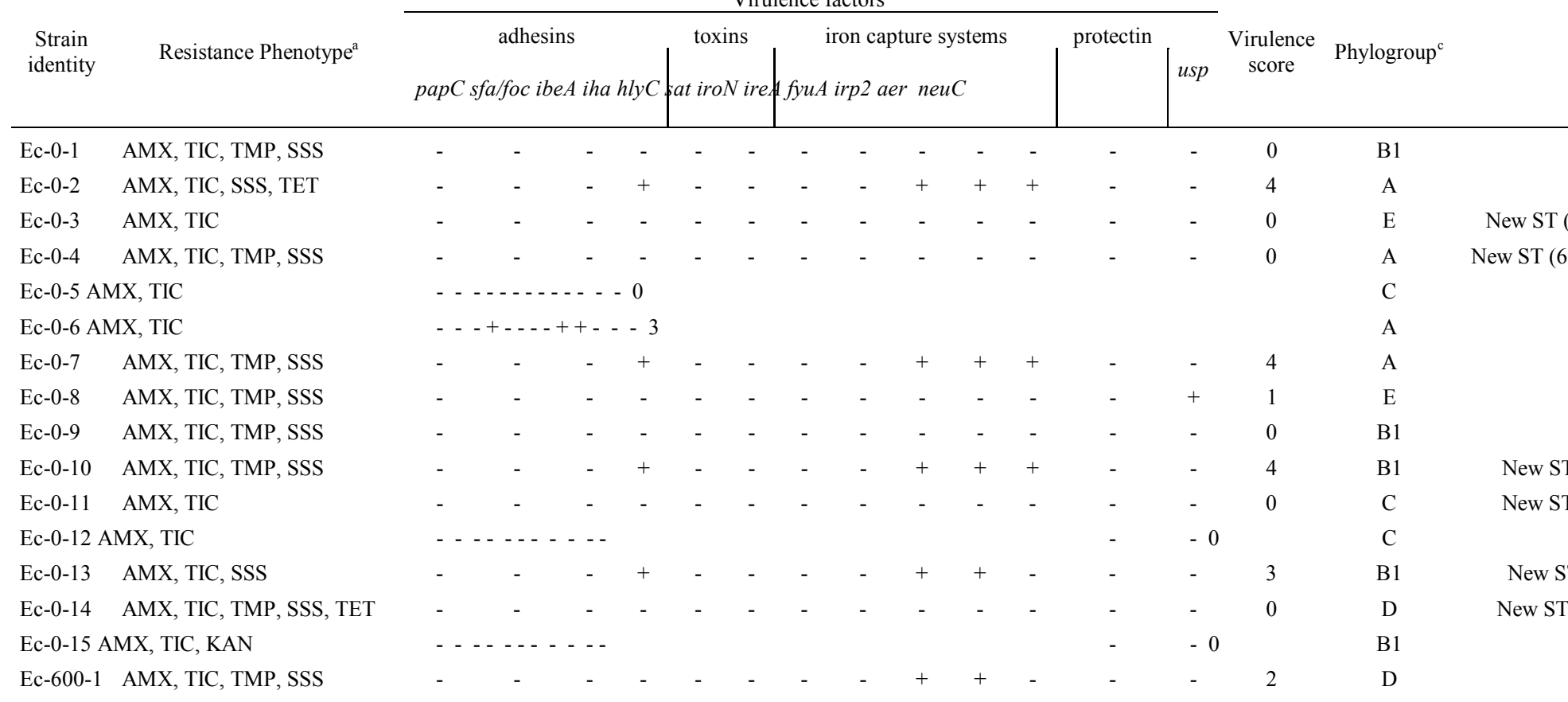

484 Table 2: Resistance phenotype, virulence factors and score, phylogroup and sequence type (ST) of E. coli stra

485 a The susceptibility of the following antibiotics were tested: amoxicillin (AMX), ticarcilline (TIC), amoxicilli

486 ceftazidime, cefepime, cefoxitin, ertapenem, gentamicin, amikacin, kanamycin (KAN), nalidixic acid, ofloxa 487 sulfonamide (SSS) and tetracycline (TET)

$488{ }^{\mathrm{b}}$ E. coli virulence factors were detected by PCR as described elsewhere (Johnson et al., 2006) and virulence 489 2011).

$490{ }^{\mathrm{c}}$ Phylogroups of $E$. coli strains were determined by quadruplex PCR as described elsewhere (Clermont et al.,

491 d Multilocus sequence typing (MLST) was performed using one of the MLST schemes developed for $E$. coli

492 (http://www.mlst.ucc.ie/mlst/dbs/Ecoli). 
${ }^{\mathrm{e}} \mathrm{T}$, transfer by electroporation; $\mathrm{C}$, transfer by mating. The transferability of TEM-1 genes was assessed by ma (Bakour et al., 1983). When mating failed, transformation into E. coli DH5 (Invitrogen) was attempted by e 495 DNA.

${ }^{\mathrm{f}}$ Resistance genes $b l a_{\text {TEM }}$ were amplified with specific primers, as described elsewhere (Saladin et al., 2002), 


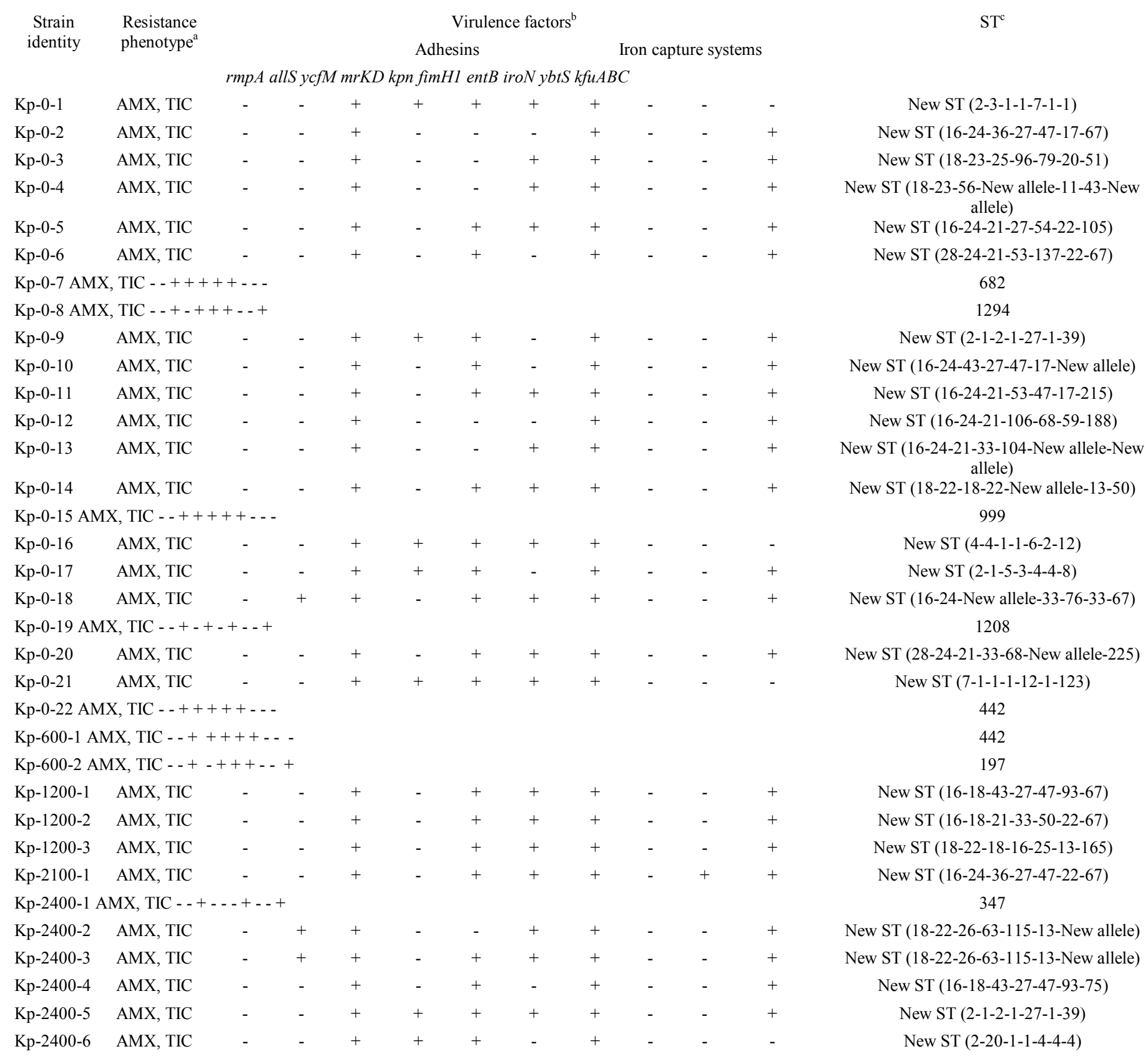

Table 3: Resistance phenotype, virulence factors and sequence type (ST) of K. pneumoniae 502 strains.

$503{ }^{\mathrm{a}}$ The susceptibility of the following antibiotics were tested: amoxicillin (AMX), ticarcilline 504 (TIC), amoxicillin + clavulanate, cefotaxime, ceftazidime, cefepime, cefoxitin, ertapenem, 505 gentamicin, amikacin, kanamycin, nalidixic acid, ofloxacin, trimethoprim, sulfonamide and 506 tetracycline

$507{ }^{\mathrm{b}}$ K. pneumoniae capsular serotypes K1 $(\operatorname{mag} A), \mathrm{K} 2, \mathrm{~K} 5, \mathrm{~K} 20, \mathrm{~K} 54$ and K57 were determined 508 using multiplex PCR, as described (Turton et al., 2008).Virulence genes were searched by 509 PCR. Primers used are reported in Table S3. Two reference strains of capsular serotypes K1 510 (NTUH K2044) and K2 (CG43) were used as controls (Chen et al., 2004; Fang et al., 2004). $511{ }^{\mathrm{c}}$ Multilocus sequence typing (MLST) was performed using the international MLST scheme of the Institut Pasteur, Paris, France (http://www.pasteur.fr/mlst) 


\begin{tabular}{|c|c|c|c|c|c|c|}
\hline \multirow[b]{2}{*}{ Cassette array } & \multicolumn{5}{|c|}{ Number of samples } & \multirow[b]{2}{*}{ Total } \\
\hline & 0 (Village) & $300 \mathrm{~m}$ & $600 \mathrm{~m}$ & $1200 \mathrm{~m}$ & $2400 \mathrm{~m}$ & \\
\hline dfrA15-cmlA4-aadA2 & $2---2$ & & & & & \\
\hline$d f r A 21-a a d A 2$ & $1---1$ & & & & & \\
\hline $\operatorname{aad} A 1$ & ---11 & & & & & \\
\hline $\operatorname{aad} A 2$ & $2---2$ & & & & & \\
\hline aadA6 & $1-1136$ & & & & & \\
\hline dfrA7 & $1---1$ & & & & & \\
\hline dfrA21 & $1--12$ & & & & & \\
\hline
\end{tabular}

Table 4: Gene cassettes arrays of class 1 integrons in microbiota of rodents and marsupials 519 ND: Not Determined

520 For the construction of gene cassette array libraries, primers 5' $\mathrm{CS}$ and 3' $\mathrm{CS}$ at $0.5 \mu \mathrm{M}$

521 (Levesque et al., 1995) were used to amplify and sequence the variable GC-containing region

522 of class 1 integrons directly from the extracted DNA $(5 \mu \mathrm{L})$ as described (Stalder et al.,

523 2013). At least 20 clones were used for sequencing. 


\section{$527 \quad$ Figure legends}

Figure 1: Study site: Trois-Sauts (in the municipality of Camopi, French Guiana: $02^{\circ} 15^{\prime} \mathrm{N}$, $\left.52^{\circ} 52^{\prime} \mathrm{W}\right)$.

Red numbers represent the number of samples per trapping point (in the village and at specific distances from the village).

Rectal swabs of trapped animal were inoculated extemporaneously onto Drigalski agar slants in screw-cup tubes and sent to France at room temperature. There, the global Drigalski culture from each tube was suspended in $1.5 \mathrm{~mL}$ of brain-heart infusion (BHI) broth with $10 \%$ glycerol and stored at $-80^{\circ} \mathrm{C}$.

Figure 2: Percentage of samples bearing natural (Klebsiella spp.) or acquired (E. coli) ticarcillin resistance according to the distance from the village, i.e. the source of antibiotic selection pressure.

Figure 3: Dendrogram and rep-PCR fingerprints of E. coli (a) and K. pneumoniae (b) strains. Strains were named by their initials (Ec for $E$. coli and $\mathrm{Kp}$ for $K$. pneumoniae), followed by the distance from the village of the isolation site, followed by the order number. The genetic relatedness was analyzed by rep-PCR DNA fingerprinting with the DiversiLab system (bioMérieux, Marcy l'Etoile, France) as in Woerther et al., 2013a.

Figure 4: Percentage of samples bearing class 1 or class 2 integrons according to the distance from the village, i.e. the source of antibiotic selection pressure. 


\begin{tabular}{|c|c|c|c|c|c|c|c|}
\hline Sample & $\begin{array}{l}\text { Distance from } \\
\text { the village }(\mathrm{m})\end{array}$ & Animal & $\begin{array}{l}\text { Rodent / } \\
\text { Marsupial }\end{array}$ & $\begin{array}{c}\text { Ticarcillin resistant } \\
\text { E. coli }\end{array}$ & Klebsiella spp. & $\begin{array}{c}\text { Class } 1 \\
\text { integron }\end{array}$ & $\begin{array}{l}\text { Class } 2 \\
\text { integron }\end{array}$ \\
\hline 1 & 0 & Nectomys rattus & Rodent & Ec-0-1 No & & -- & \\
\hline 2 & 0 & Nectomys rattus & Rodent & No Kp-0-1 & & -- & \\
\hline 3 & 0 & Nectomys rattus & Rodent & No Kp-0-2 & & -- & \\
\hline 4 & 0 & Nectomys rattus & Rodent & No No & & -- & \\
\hline 5 & 0 & Philander opossum & Marsupial & No No & & - - & \\
\hline 6 & 0 & Makalata didelphoides & Rodent & No Kp-0-3 & & -- & \\
\hline 7 & 0 & Nectomys rattus & Rodent & No No & & - - & \\
\hline 8 & 0 & Makalata didelphoides & Rodent & No Kp-0-4 & & -- & \\
\hline 9 & 0 & Marmosa murina & Marsupial & No Kp-0-5 & & - - & \\
\hline 10 & 0 & Nectomys rattus & Rodent & No No & & -- & \\
\hline 11 & 0 & Nectomys rattus & Rodent & No No & & - - & \\
\hline 12 & 0 & Nectomys rattus & Rodent & No No & & -- & \\
\hline 13 & 0 & Marmosa murina & Marsupial & No No & & - - & \\
\hline 14 & 0 & Oecomys bicolor & Rodent & No Kp-0-6 & & +- & \\
\hline 15 & 0 & Hylaeamys megacephalus & Rodent & No No & & -- & \\
\hline 16 & 0 & Nectomys rattus & Rodent & Ec-0-2 Kp-0-7 & & -- & \\
\hline 17 & 0 & Marmosa murina & Marsupial & No No & & +- & \\
\hline 18 & 0 & Nectomys rattus & \multicolumn{3}{|c|}{ Rodent No No } & -- & \\
\hline \multicolumn{3}{|c|}{190 Proechimys cuvieri } & \multicolumn{3}{|c|}{ Rodent No No } & -- & \\
\hline \multicolumn{3}{|c|}{200 Oecomys bicolor } & \multicolumn{3}{|c|}{ Rodent No No } & -- & \\
\hline 21 & 0 & Nectomys rattus & \multicolumn{3}{|c|}{ Rodent No No } & -- & \\
\hline 22 & 0 & Nectomys rattus & \multicolumn{3}{|c|}{ Rodent No No } & -- & \\
\hline 23 & 0 & Nectomys rattus & \multicolumn{3}{|c|}{ Rodent Ec-0-3 No } & -- & \\
\hline 24 & 0 & Nectomys rattus & \multicolumn{3}{|c|}{ Rodent No No } & -- & \\
\hline \multicolumn{3}{|c|}{250 Oecomys bicolor } & \multicolumn{3}{|c|}{ Rodent No No } & -- & \\
\hline \multicolumn{3}{|c|}{260 Oecomys bicolor } & \multicolumn{3}{|c|}{ Rodent No No } & -- & \\
\hline \multicolumn{3}{|c|}{270 Oecomys bicolor } & \multicolumn{3}{|c|}{ Rodent No No } & -- & \\
\hline \multicolumn{3}{|c|}{280 Hylaeamys megacephalus } & \multicolumn{3}{|c|}{ Rodent No No } & -+ & \\
\hline 290 & & Nectomys rattus & \multicolumn{3}{|c|}{ Rodent No No } & -- & \\
\hline 300 & & Nectomys rattus & \multicolumn{3}{|c|}{ Rodent Ec-0-4, Ec-0-5 Kp-0-8 } & +- & \\
\hline \multicolumn{3}{|c|}{310 Oecomys bicolor } & \multicolumn{3}{|c|}{ Rodent No $K$. oxytoca } & +- & \\
\hline $320 C$ & ecomys bicolor & & Rodent Ec- & $-0-6$, Ec-0-7 Kp-0-9 & & +- & \\
\hline $330 \mathrm{C}$ & ecomys bicolor & & Rodent No & No & & -- & \\
\hline 340 & & Nectomys rattus & Rodent No & No & & -- & \\
\hline $350 N$ & eusticomys oyap & ocki & Rodent No & $\mathrm{Kp}-0-10$ & & -- & \\
\hline 360 & & Nectomys rattus & Rodent No & No & & -- & \\
\hline 370 & & Nectomys rattus & Rodent No & $\mathrm{Kp}-0-11$ & & -- & \\
\hline $380 P$ & roechimys cuvier & & Rodent No & No & & -- & \\
\hline 390 & & Nectomys rattus & Rodent Ec- & $-0-8 \mathrm{No}$ & & - - & \\
\hline 400 & & Nectomys rattus & Rodent No & No & & +- & \\
\hline 410 & & Nectomys rattus & Rodent No & No & & -- & \\
\hline 420 & & Nectomys rattus & Rodent No & $\mathrm{Kp}-0-12$ & & -- & \\
\hline 430 & & Nectomys rattus & Rodent No & $\mathrm{Kp}-0-13$ & & - - & \\
\hline 440 & & Nectomys rattus & Rodent No & $\mathrm{Kp}-0-14$ & & -- & \\
\hline 450 & & Nectomys rattus & Rodent No & No & & -- & \\
\hline 460 & & Nectomys rattus & Rodent No & No & & -- & \\
\hline 470 & & Nectomys rattus & Rodent No & No & & -- & \\
\hline $480 \mathrm{~N}$ & Iarmosa murina & & Marsupial & No Kp-0-15 & & +- & \\
\hline
\end{tabular}


500 Marmosa murina

510 Hylaeamys megacephalus

$$
520 \quad \text { Nectomys rattus }
$$

530 Hylaeamys megacephalus

$540 \quad$ Nectomys rattus

550 Proechimys cuvieri

$560 \quad$ Nectomys rattus

570 Oecomys bicolor

580 Philander opossum

590 Hylaeamys megacephalus

600

Nectomys rattus

610 Marmosa murina

620 Oecomys bicolor

630 Oecomys bicolor

640 Oecomys bicolor

650

Nectomys rattus

660 Hylaeamys megacephalus

$670 \quad$ Nectomys rattus

680 Oecomys bicolor

690 Oecomys bicolor

700 Oecomys bicolor

710

Nectomys rattus

720

Nectomys rattus

730 Marmosa murina

$\begin{array}{lll}74 & 300 & \text { Marmosa murina } \\ 75 & 300 & \text { Nectomys rattus }\end{array}$

76300 Proechimys cuvieri

77300 Oecomys rutilus

78600 Didelphis marsupialis

79600 Hylaeamys megacephalus

80600 Neacomys paracou

81600 Hylaeamys megacephalus

82600 Proechimys cuvieri

83600 Proechimys cuvieri

84600 Hylaeamys megacephalus

85600 Proechimys cuvieri

86600 Hylaeamys megacephalus

$\begin{array}{lcl}87 & 900 & \text { Proechimys cuvieri } \\ 88 & 1200 & \text { Proechimys cuvieri } \\ 89 & 1200 & \text { Proechimys cuvieri }\end{array}$

901200 Hylaeamys megacephalus

911200 Proechimys cuvieri

921200 Proechimys cuvieri

931200 Proechimys guyannensis

941200 Proechimys cuvieri

951200 Euryoryzomys macconnelli

961200 Hylaeamys megacephalus

971200 Didelphis imperfecta

981200 Proechimys cuvieri

$\begin{array}{ccc}99 & 1500 & \text { Proechimys cuvieri } \\ 100 & 2100 & \text { Proechimys cuvieri }\end{array}$

Rodent No No

Marsupial No Kp-0-16

Rodent No Kp-0-17

Rodent Ec-0-9 No

Rodent No No

Rodent No No

Rodent No Kp-0-18

Rodent No No

Rodent No No

Marsupial Ec-0-10 Kp-0-19

Rodent No No

Rodent No No

Marsupial No No

Rodent No No

Rodent No No

Rodent No No

Rodent No No

Rodent No No

Rodent No No

Rodent No No

Rodent No No

Rodent No Kp-0-20

Rodent No No

Rodent Ec-0-11, Ec-0-12 Kp-0-21

Marsupial $\begin{gathered}\text { Ec-0-13, Ec-0-14, } \\ \text { Ec-0-15 }\end{gathered}$

Marsupial No No

Rodent No No

Rodent No No

Rodent No No

Marsupial Ec-600-1 No

Rodent No Kp-600-1

Rodent No No

Rodent No No

Rodent No No

Rodent No No

Rodent No No

Rodent No Kp-600-2

Rodent No No

Rodent

No No

Rodent

No Kp-1200-1

Rodent

No No

Rodent No No

Rodent No No

Rodent No No

Rodent No Kp-1200-2

Rodent No No

Rodent No No

Rodent No Kp-1200-3

Marsupial No No

Rodent No No

Rodent

No

Rodent No Kp-2100-1
-

$+$

- -

$-$

$-$

- -

$--$

- -

- -

$+$

- -

$--$

-

- -

- -

$-$

$-$

$-$

- -

$+$

- -

$--$

$++$

$+$

- -

-

$+$

-

$-$

-

$-$

$--$

- -

$--$

-

$+$

-

-

-

- -

$-$

$+$

-

-

- 
1012400 Marmosa demerarae

1022400 Oecomys rutilus

1032400 Proechimys cuvieri

1042400 Proechimys cuvieri

1052400 Proechimys cuvieri

1062400 Proechimys cuvieri

1072400 Proechimys cuvieri

1082400 Proechimys guyannensis

1092400 Proechimys cuvieri

1102400 Marmosops pinheiroi

1112400 Hylaeamys megacephalus

$112 \quad 2700 \quad$ Proechimys guyannensis

1133000 Proechimys cuvieri

1143000 Euryoryzomys macconnelli
Marsupial No No

Rodent No No

Rodent No No

Rodent No Kp-2400-1

Rodent No Kp-2400-2

Rodent No Kp-2400-3

Rodent No Kp-2400-4

Rodent No No

Rodent No Kp-2400-5

Marsupial No Kp-2400-6

Rodent No No

Rodent

No No

Rodent No No

Rodent No No
560

561

562

563

564

565

\begin{tabular}{c}
$\begin{array}{c}\text { Distance from } \\
\text { the village }(\mathrm{m})\end{array}$ \\
\hline 01047 \\
300786 \\
6001341 \\
900241 \\
12001341 \\
1500241 \\
1800786 \\
2100241 \\
24001341 \\
2700241 \\
30001341
\end{tabular}

566 Table S2: Sampling effort (trap-nights) over the three campaigns (October 2006, June 2008, 567 and October 2010) according to the distance from the village. 


\begin{tabular}{|c|c|c|c|}
\hline Name DNA sequence & $\begin{array}{c}\text { Target } \\
\text { site }\end{array}$ & $\begin{array}{l}\text { Amplicon } \\
\text { size }(\mathrm{pb})\end{array}$ & Reference \\
\hline $\begin{array}{l}\text { ycfM-F 5'-CGATTGAGCATCAGGATCAG-3' ycfM } \\
\text { ycfM-R 5'-GTTGGTGCGGTTGTTCAC-3' }\end{array}$ & \multicolumn{3}{|c|}{161 This study } \\
\hline mrkD-1 5'-TAT(T/C)G(G/T)CTTAATGGCGCTGG-3' mrkD & & 920 & $\begin{array}{l}\text { Brisse et al. (Brisse } \\
\text { et al., 2009) }\end{array}$ \\
\hline 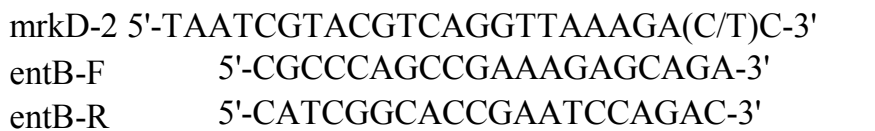 & & \multicolumn{2}{|c|}{508 This study } \\
\hline $\begin{array}{l}\text { ybtS-F 5'-CAAAAATGGGCGGTGGATTC-3' ybtS } \\
\text { ybtS-R 5'-CCTGACGGAACATAAACGAGCG-3' }\end{array}$ & & & $\begin{array}{l}\text { Bachman et al. } \\
\text { (Bachman et al., } \\
\text { 2011) }\end{array}$ \\
\hline $\begin{array}{l}\text { kfu-F 5'-ATAGTAGGCGAGCACCGAGA-3' kfu } \\
\text { kfu-R 5'-AGAACCTTCCTCGCTGAACA-3' }\end{array}$ & & 520 & $\begin{array}{l}\text { Yu et al. (Yu et al., } \\
\text { 2008) }\end{array}$ \\
\hline $\begin{array}{l}\text { iroN-F 5'-GCATAGGCGGATACGAACAT-3' iroN } \\
\text { iroN-R 5'-CACAGGGCAATTGCTTACCT-3' }\end{array}$ & & 556 & $\begin{array}{l}\text { Yu et al. (Yu et al., } \\
\text { 2008) }\end{array}$ \\
\hline magA-F 5'-GGTGCTCTTTACATCATTGC-3' magA & & 1280 & $\begin{array}{l}\text { Fang et al. (Fang et } \\
\text { al., 2004) }\end{array}$ \\
\hline magA-R 5'-GCAATGGCCATTTGCGTTAG-3' & & & \\
\hline 1416R 5'-CCGTTAGGCAATCCAGAC-3' alls & & 1090 & $\begin{array}{l}\text { Chou et al. (Chou } \\
\text { et al., 2004) }\end{array}$ \\
\hline 336F2 5'TCTGATTTA(A/T)CCCACATT-3' & & & \\
\hline rmpA-F 5'-ACTGGGCTACCTCTGCTTCA-3' rmpA & & 535 & $\begin{array}{l}\text { Brisse et al. (Brisse } \\
\text { et al., 2009) }\end{array}$ \\
\hline
\end{tabular}

Table S3: Primers used for characterization of K. pneumoniae virulence factors 